\title{
DETERMINACIJA SPOLA I MORFOLOŠKE OSOBINE SIVOG PUHA (GLIS GLIS) S PODRUČJA DALMATINSKE ZAGORE
}

\section{DETERMINATION OF SEX AND MORPHOLOGICAL CHARACTERISTICS OF FAT DORMOUSE (GLIS GLIS) FROM THE AREA OF DALMATIAN HINTERLAND}

\author{
Ivan PERVAN1', Tena RADOČAJ1, Tea TOMLJANOVIĆ', Miljenko BUJANIĆ2 ${ }^{2}$ Dean KONJEVIĆ
}

\begin{abstract}
SAŽETAK
Sivi puh (Glis glis L.) je najveći pripadnik porodice puhova. Arborealna je i nokturnalna životinja koja je autohtona vrsta divljači u Hrvatskoj. U radu su obrađeni morfološki parametri, kao što su mase (tijelo s repom, tijelo bez repa, glava, rep, jetra, bubreg, srce, pluća, puno probavilo i radman) i duljine pojedinih dijelova tijela (tijelo s repom, tijelo bez repa, rep te raspon prednjih i stražnjih udova), izmjereni na 32 adultne jedinke (18 ženki i 14 mužjaka) ulovljenim tijekom lovne sezone 2017./2018.) na području Dalmatinske zagore. Statistički značajna razlika između mužjaka i ženki utvrđena je u duljini tijela bez repa $(\mathrm{p}=0,049)$ i masi repa $(\mathrm{p}=0,041)$, mužjaci imaju veće vrijednosti za obje značajke. Ostali izmjereni parametri nisu pokazali statitistički značajnu razliku između spolova. Spolni dimorfizam kod ovog glodavca nije izražen, iako mužjaci u prosjeku imaju nešto veću masu od ženki. Na temelju boje krzna i veličine tijela nije moguće razlikovati adultne od juvenilnih jedinki. Izmjereni morfološki parametri uglavnom se podudaraju s rezultatima sličnih istraživanja.
\end{abstract}

KLJUČNE RIJEČl: sivi puh (Glis glis L.), Dalmatinska zagora, morfologija, spolni dimorfizam

\section{UVOD}

\section{INTRODUCTION}

Puhovi (Gliridae) su stara porodica u redu glodavaca (Rodentia) te rijetka skupina sisavaca koji imaju europsko porijeklo (Barret-Hamilton 1898., 1899., Hürner i sur. 2010.). Prema najnovijoj podjeli utemeljenoj na molekularnim analizama puhovi se ubrajaju u skupinu Boreoeutheria, granu Euarchontoglires, red Rodentia i porodicu Gliridae (Murphy i sur. 2001.). U zapadnoj Europi pronađeni su najstariji fosilni ostaci puhova još s početka eocena, razdoblja od prije 50 milijuna godina. Vrhunac razvoja puhova događa se razdoblju od miocena (prije 26 milijuna godina) pa sve do unatrag 5 milijuna godina. Sva novija istraživanja ukazuju da je u to vrijeme istodobno živjelo više od 35 vrsta ove porodice. U sljedećem geološkom razdoblju, pleocenu, u Europu iz Azije prodiru razne vrste miševa (Murinae) i voluharice (Arvicolinae), što dovodi do smanjenja broja vrsta puhova (Daams 1999., Horaček 1986.). U središnjoj Europi dobro su sačuvana fosilna nalazišta puhova iz kasnog plestiocena i holocena (Aguilar i sur. 1998., Kowalski 2001.).

Središnju Europu danas nastanjuju četiri vrste puhova, pri čemu su na tom području najčešće pronađeni fosilni ostaci sivoga ili velikoga puha (Glis glis L.), a najrjeđe gorskoga

\footnotetext{
${ }^{1}$ Ivan Pervan, mag. ing. agr., Tena Radočaj, mag. ing. agr., Izv. prof. dr. sc. Tea Tomljanović, Agronomski fakultet Sveučilišta u Zagrebu, Svetošimunska 25, Zagreb, Hrvatska (e-mail: ivan.pervan10@gmail.com)

${ }^{2}$ Dr. sc. Miljenko Bujanić, dr. med. vet., Izv. prof. dr. sc. Dean Konjević, Sveučilište u Zagrebu, Veterinarski fakultet, Heinzelova 55, Zagreb, Hrvatska
} 
puha (Dryomys nitedula Pall.) (Filippucci i Kotsakis 1995.). Brojnost sivoga puha posebice se povećava u godinama bogatog uroda bukvice koja mu je važna hrana (Amori i sur. 1995., Bieber, 1998.; Cvrtila i sur. 2004., Margaletić i sur. 2004.; Grubešić i sur. 2004., 2007.). Sivog puha ovisno o klimi i nadmorskoj visini najčešće primijećujemo u drugoj polovini travnja i u svibnju. Posljedica smanjenja brojnosti populacije sivog puha u nekim dijelovima Europe najčešće se pripisuje gubitku staništa uslijed nekontroliranih sječa i intenzivnog gospodarenja šumama, međutim pravi razlog pada brojnosti još uvijek nije u potpunosti razriješen (Jurczysczyn 1994., 2001., Jurczysczyn i Wolk 1998.). Prema Zakonu o lovstvu (Anonimus, 2018.) sivi ili veliki puh je divljač u Republici Hrvatskoj i to samo na području južno od rijeke Save, dok gorski puh (Dryomys nitedula Pall.) i puh lješnikar (Muscardinus avellanarius L.) nisu na popisu divljači i spadaju u strogo zaštićen vrste (Anonimus, 2013.), a endemski krški puh (Eliomys quercinus dalmaticus L.), nije ni na popisu divljači ni na popisu strogo zaštićenih vrsta. Ciljevi ovoga istraživanja bili su: i) prikazati osnovne morfološke značajke sivog puha s područja Dalmatinske zagore, ii) utvrditi da li je moguće razlikovati spol na temelju veličine tijela i boje krzna, iii) usporedno prikazati mužjake i ženke na temelju morfoloških karakteristika.

\section{MATERIJALI I METODE MATERIAL AND METHODS}

Istraživanje je provedeno na području Dalmatinske zagore. Reljefno gledano područje istraživanja spada u nizinskobrdski tip. Osobitost reljefa je da središnjim dijelom dominira dolina, dok je sa sjeverozapadne, sjeverne, sjeveroistočne $\mathrm{i}$ jugoistočne strane teren brdovit $s$ nadmorskim visinama od $200 \mathrm{~m}$ kod Velikog Prologa do $480 \mathrm{~m}$ podno brda Gradina (Slika 1). Radi se o tipičnim krajobraznim značajkama istočno jadranskog krškog zaleđa u kojemu na nagnutim terenima dominiraju skeletna i skeletoidna tla, a u dolinama je došlo do sakupljanja zemlje u debljem sloju (Anonimus 2008.).

Uzorkovanje se provodilo tijekom jedne godine, sukladno Pravilniku o lovostaji (Anonimus, 2010.) od 1. listopada do 30. studenoga (20 jedinki), dok je 12 jedinki sakupljeno izvan razdoblja puholova (mortaliteti izazvani drugim uzrocima). Ukupno su sakupljene 32 adultne jedinke (14 mužjaka i 18 ženki). Nakon prikupljanja, svaki uzorak je stavljen u PVC vrećicu, označen i pohranjen u zamrzivač na $-22{ }^{\circ} \mathrm{C}$, do daljnje analize. Po različitoj udaljenosti vanjskog spolnog organa i analnog otvora vizualnim pregledom određen je spol životinje. Masa jedinki izmjerena je vagom

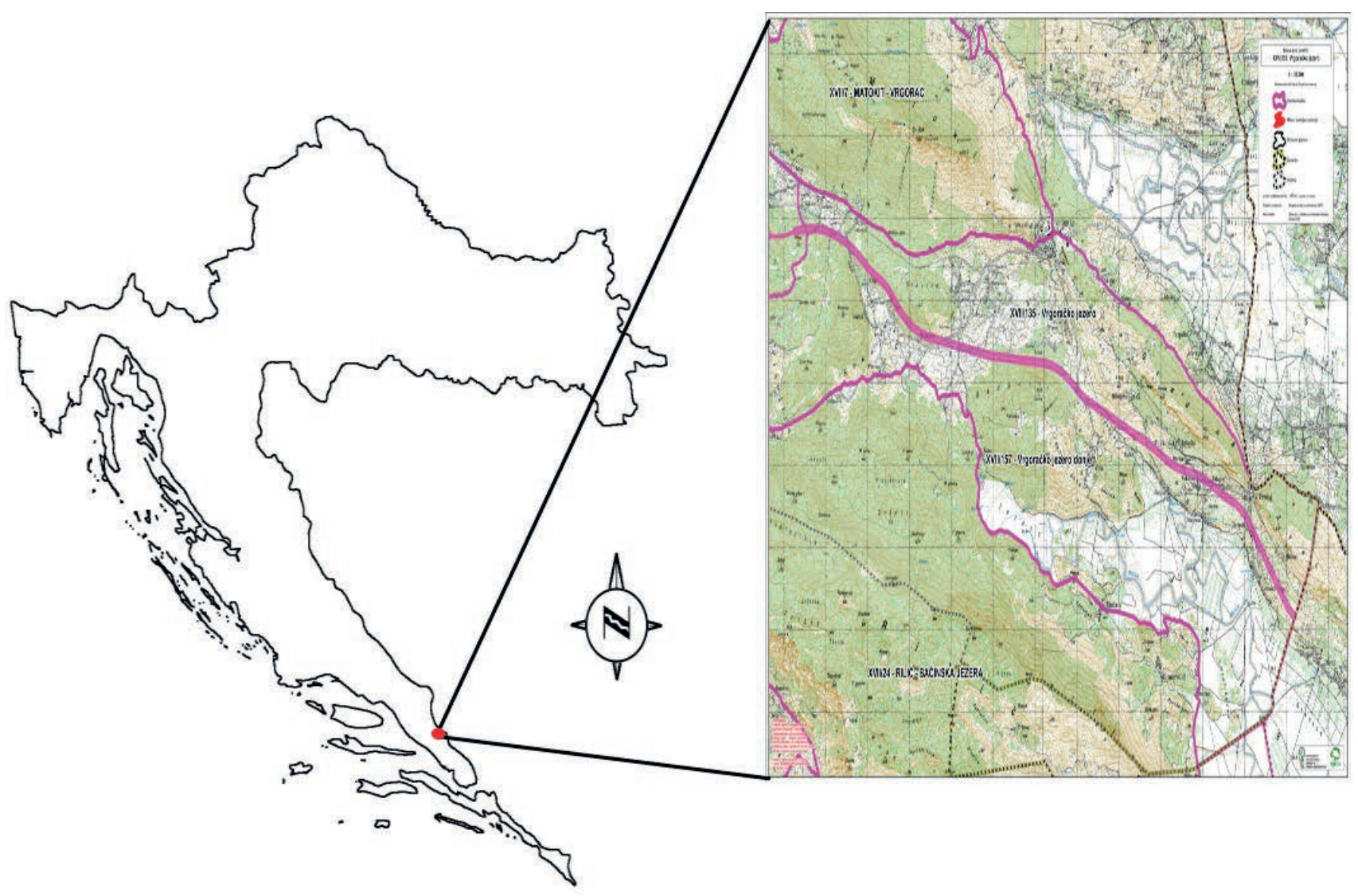

Slika 1: Područje istraživanja

Figure 1: Study area

Izvor: http://www.mps.hr/hr/sume/lovstvo/sredisnja-lovna-evidencija 


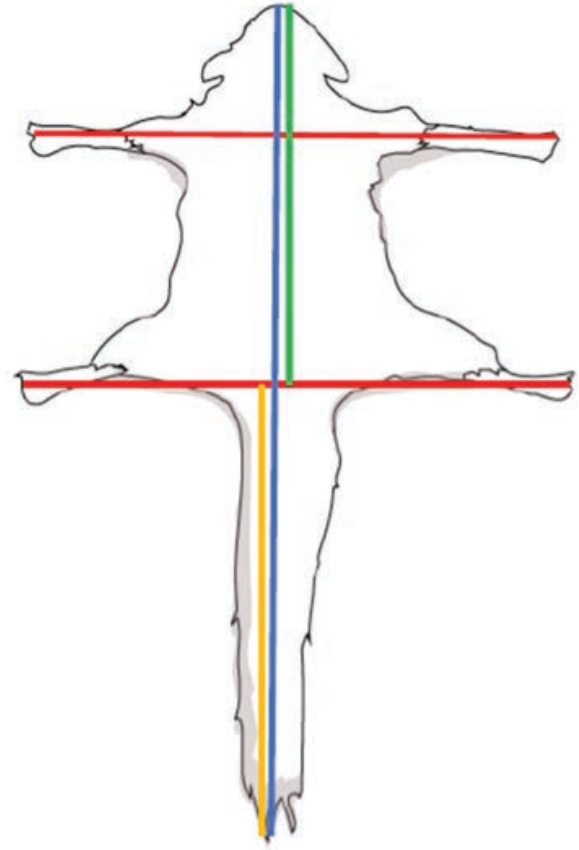

Slika 2: Skica sivog puha-s izmjerama: raspon prednjih i stražnjih udova puha (crvena linija), ukupne duljine tijela (plava linija), duljine tijela bez repa (zelena linija) i duljine repa (smeđa linija)

Figure 2: Draft Edible dormouse with measurements: front and back limb width (red line), total body length (blue line), length of body without tail (green line) and tail length (brown line)

marke Radwag PS, s preciznošću od $\pm 0,001 \mathrm{~g}$ te je iskazana u gramima. Duljina tijela mjerena je mjernom vrpcom točnosti $\pm 1 \mathrm{~mm}$. Raspon prednjih i stražnjih udova i duljina repa mjerena je digitalnom pomičnom mjerkom, s točnošću na dvije decimale.
Za prikaz dobivenih morfoloških vrijednosti određene su: srednja vrijednost (x), minimum (min), maksimum (max), standardna devijacija (sd) i standardna greška (sd error). Izračunate su i korelacije između morfoloških osobina. Za analizu podataka primijenjeni su računalno-statitistički programi R, R studio iSPSS. Za dobivanje rezultata koristili smo t-test nezavisnih uzoraka. T- test nezavisnih uzoraka upotrebljavamo za uspoređivanje srednje vrijednosti neprekidne promjenjive varijable u dvije različite grupe subjekata ili u različitim okolnostima (Pallant 2007.).

\section{REZULTATI RESULTS}

Vrijednosti svih izmjerenih parametara prikazane su u tablici 1. Iz tablice možemo vidjeti podatke o minimalnoj, maksimalnoj i srednjoj vrijednosti dobivenih mjera te standardnu devijaciju koja se tumači kao prosječno odstupanje od prosjeka i to u apsolutnom iznosu. Rezultati t-testa prikazani su u posljednjem stupcu te iz njega možemo očitati da li neka veličina pokazuje statistički značajnu razliku između spolova sivog puha, pod pretpostavkom da varijance nisu jednake tj. $\mathrm{p} \leq 0,05$. Minimalna vrijednost mase mužjaka iznosila je 102,30 g, a maksimalna 215,10 g. Prosječna masa bila je 126,10 g. Mase ženki kretale su se od minimalnih 81,06 g, do maksimalnih 152,30 g. Srednja vrijednost iznosila je $114,69 \mathrm{~g}$. Iako su mužjaci u prosjeku teži i veći od ženki, možemo isčitati podatke o rasponu prednjih i stražnjih udova koji je u srednjoj vrijednosti na strani ženki. Tako maksimalni raspon prednjih udova kod ženki iznosio

Tablica 1: Skupna statistika svih istraživanih jedinki Table 1: Collective statistics of all examined individuals

\begin{tabular}{|c|c|c|c|c|c|c|c|c|c|}
\hline \multirow{2}{*}{$\begin{array}{l}\text { Parametri } \\
\text { Parameters }\end{array}$} & \multicolumn{2}{|c|}{$\begin{array}{l}\text { Artimetička sredina } \\
\text { Sritmetic mean }\end{array}$} & \multicolumn{2}{|c|}{ Min } & \multicolumn{2}{|c|}{ Max } & \multicolumn{2}{|c|}{$\mathrm{Sd}$} & \multirow{2}{*}{$\begin{array}{l}\text { T-test } \\
\mathrm{p} \text {-value }\end{array}$} \\
\hline & M & $\mathrm{F}$ & M & $\mathrm{F}$ & M & $\mathrm{F}$ & M & $\mathrm{F}$ & \\
\hline $\begin{array}{l}\text { Total mass including tail }(\mathrm{g}) \\
\text { Ukupna masa s repom (g) }\end{array}$ & 126.01 & 114.69 & 102.30 & 81.06 & 215.1 & 152,30 & 29,82089 & 23,34874 & 0.2508 \\
\hline $\begin{array}{l}\text { Total mass without tail }(\mathrm{g}) \\
\text { Ukupna masa bez repa }(\mathrm{g})\end{array}$ & 120.29 & 110.13 & 98.05 & 76.90 & 227.66 & 147.52 & 40.36951 & 22.94974 & 0.1676 \\
\hline $\begin{array}{l}\text { Body length including tail }(\mathrm{cm}) \\
\text { Duljina tijela s repom }(\mathrm{cm})\end{array}$ & 31.97 & 31.11 & 27.70 & 28.30 & 34.06 & 39.00 & 1.788849 & 2.362424 & 0.2519 \\
\hline $\begin{array}{l}\text { Body length without tail }(\mathrm{cm}) \\
\text { Duljina tijela bez repa }(\mathrm{cm})\end{array}$ & 16.26 & 15.46 & 14.90 & 13.90 & 18.90 & 17.50 & 1.116731 & 1.066130 & 0.04915 \\
\hline $\begin{array}{l}\text { Tail length }(\mathrm{cm}) \\
\text { Duljina repa }(\mathrm{cm})\end{array}$ & 15.78 & 15.59 & 12.20 & 11.30 & 18.00 & 25.80 & 1.480218 & 2.916333 & 0.9053 \\
\hline $\begin{array}{l}\text { Front limb range }(\mathrm{mm}) \\
\text { Raspon prednjih udova }(\mathrm{mm})\end{array}$ & 139.06 & 142.90 & 114.1 & 134.2 & 162.0 & 153.1 & 14.35841 & 6.03030 & 0.3671 \\
\hline $\begin{array}{l}\text { Rear limb range (mm) } \\
\text { Raspon stražnjih udova (mm) }\end{array}$ & 164.01 & 174.86 & 127.4 & 153.4 & 191.0 & 191.0 & 21.996981 & 8.659423 & 0.103 \\
\hline Tail mass $(\mathrm{g}) /$ Masa repa $(\mathrm{g})$ & 5.78 & 4.55 & 3.136 & 3.183 & 9.380 & 6.300 & 1.9524053 & 0.8834921 & 0.04127 \\
\hline
\end{tabular}


Tablica 2: Usporedba ukupne mase jedinki s lokacije Gorskog kotara (preuzeto iz Margaletić i sur. (2011.)) i Dalmatinske zagore u gramima.

\begin{tabular}{|c|c|c|c|c|}
\hline \multirow[b]{2}{*}{$\begin{array}{l}\text { Parametri/ } \\
\text { Parameters }\end{array}$} & \multicolumn{2}{|c|}{$\begin{array}{c}\text { UKUPNA MASA }(\mathrm{g}) / \text { TOTAL } \\
\text { BODY MASS }(\mathrm{g})\end{array}$} & \multicolumn{2}{|c|}{$\begin{array}{l}\text { DULJINA TIJELA }(\mathrm{cm}) / \\
\text { BODY LENGTH }(\mathrm{cm})\end{array}$} \\
\hline & Gorski kotar & $\begin{array}{c}\text { Dalmatinska } \\
\text { zagora/ } \\
\text { Dalmatian } \\
\text { hinterland }\end{array}$ & Gorski kotar & $\begin{array}{c}\text { Dalmatinska } \\
\text { zagora/ } \\
\text { Dalmatian } \\
\text { hinterland }\end{array}$ \\
\hline $\begin{array}{l}\text { ARIT. SREDINA/ } \\
\text { Arit. mean }\end{array}$ & 30,56 & 31,49 & 114,89 & 119,68 \\
\hline Median & 31 & 31,55 & 115 & 115,29 \\
\hline Min & 23,5 & 27,7 & 55 & 81,06 \\
\hline Max & 43 & 39 & 250 & 215,07 \\
\hline St.dev & 2,89 & 2,14 & 32,46 & 26,55 \\
\hline St.Err & 0,18 & 0,38 & 2,06 & 4,69 \\
\hline
\end{tabular}

je 153,10 mm, a kod mužjaka $162 \mathrm{~mm}$, gdje je za srednju dužinu prednjih udova kod ženki rezultat $142,90 \mathrm{~mm}$, a kod mužjaka 139,06 milimetara. Minimalne vrijednosti raspona prednjih udova kod ženki iznosile su $134,20 \mathrm{~mm}$, a kod mužjaka 114,10 mm. Najveći raspon stražnjih udova i kod mužjaka i kod ženke izmjeren je u vrijednosti od $191 \mathrm{~mm}$. U prosječnom i minimalnom rasponu stražnjih udova ženke pokazuju izraženije vrijednosti. Minimalni raspon stražnjih udova kod ženke iznosio je $153,40 \mathrm{~mm}$, srednja vrijednost za ženke mjereći raspon stražnjih udova je 174,86 $\mathrm{mm}$. U slučaju muških jedinki, minimalna vrijednost je $127,40 \mathrm{~mm}$, srednja vrijednost za raspon stražnjih udova kod mužjaka iznosila je 164,01 mm.

Vjerojatnost hipoteze duljine tijela bez repa prema spolu iznosi 0,049 . Srednja vrijednost u mužjaka iznosi $16,26 \mathrm{~cm}$, a srednja vrijednost u ženki $15,46 \mathrm{~cm}$. Minimalna vrijednost duljine tijela bez repa izmjerena kod mužjaka iznosila je $14,90 \mathrm{~cm}$, a kod ženke $13,90 \mathrm{~cm}$. Maksimalne vrijednosti kod mužjaka i ženke bile su $18,90 \mathrm{~cm}$ i $17,50 \mathrm{~cm}$ u korist mužjaka.

Vjerojatnost hipoteze mase repa s obzirom na spol iznosi 0,041 . Srednja vrijednost u mužjaka iznosi $5,78 \mathrm{~g}$, dok u ženki iznosi 4,55 g. Maksimalne vrijednosti su u korist mužjaka, gdje je najveća izmjerena masa bila 9,380 g, a kod ženki $6,300 \mathrm{~g}$.

Pomoću tabličnog prikaza (tablica 2), usporedili smo duljine tijela i ukupne mase puhova s lokaliteta Gorskog kotara i lokaliteta Dalmatinske zagore. U tablici su prikazane srednje vrijednosti, median, minimalne mjere, maksimalne mjere, standardna devijacija i standardna pogreška. Vidljivo je da su puhovi s lokaliteta Gorskog kotara u prosjeku neznatno lakši, odnosno kraći. Maksimalne vrijednosti duljine tijela i ukupne mase puhova s područja Gorskog kotara, premašuju iste $s$ područja Dalmatinske zagore. Minimalne mjere u našim prikazima su u korist puhova s lokaliteta Dalmatinske zagore. Odnosno, minimalne vri- jednosti duljine tijela i ukupne mase puhova s lokaliteta Dalmatinske zagore, premašuju minimalne vrijednosti dobivenih u istraživačkom radu na području Gorskog kotara. Mediani za „ukupnu masu“ se podudaraju, gdje za duljinu tijela vidimo da blagu korist imaju puhovi s lokaliteta Dalmatinske zagore. Za razliku od srednjih vrijednosti, maksimalne vrijednosti duljine tijela i ukupne mase, veće su u slučaju puhova s područja Gorskog kotara. U skladu s navedenim pokazateljima očekivano je da su puhovi s lokaliteta Gorskog kotara u prosjeku neznatno lakši, odnosno da su duljine tijela bez repa nešto kraće.

\section{RASPRAVA}

\section{DISCUSSION}

Tjelesna masa puhova je razmjerno često istraživan parametar ove vrste te je moguće pronaći velik broj podataka za različite lokalitete. Ovdje je važno zamijetiti kako su puhovi u ovom istraživanju nešto većih masa od puhova u drugim istraživanjima na području Europe. S obzirom na blizinu područja masu puhova smo usporedili s podacima dobivenim u istraživanju na području Gorskog kotara (Margaletić i sur. 2011.). Pri tome Margaletić i sur. (2011.) navode kako je prosječna masa svih ispitanih uzoraka iznosila $115 \mathrm{~g}$, što se poklapa s istraživanjem u ovome radu gdje prosjek ukupne mase iznosi 115,29 g. Tako Margaletić i sur. (2011.) navode da srednja vrijednost duljine tijela puhova iz Gorskog Kotara iznosi 30,56 cm. Srednja vrijednost duljine tijela u našem istraživanju iznosila je $31,49 \mathrm{~cm}$, maksimalna 39,0 ; a minimalna $27,7 \mathrm{~cm}$. Podaci o broju ulovljenih jedinki po spolu i lokalitetu kod Margaletić i sur. (2011.) otkrivaju da omjer ukupno ulovljenih mužjaka i ženki ide u korist ženki. Navedeno je u suglasnosti s našim istraživanjem, gdje je također prisutan nešto veći broj ženki (18), u odnosu na mužjake u istraživanju (14). Margaletić i sur. (2011.) ne pronalaze statistički značajnu razliku ni po lokalitetima ni po spolu, što je uglavnom sukladno s ovim istraživanjem, budući da je statistički značajna razlika između mužjaka i ženki pronađena jedino kod mase repa i kod duljine tijela bez repa. U dosadašnjim istraživanjima maksimalna zabilježena masa sivog puha s područja Gorskog Kotara iznosila je $380 \mathrm{~g}$ (Tvrtković i sur. 1996.), za područje srednje Slovenije 476 g (Kryštufek i Flajšman 2007.). Međutim, razlika u masama može biti signifikantna čak i ako se radi i međusobno udaljenim lokalitetima istog područja (Grubešić i sur. 2004.). Tako je prosječna masa puhova (i juvenilnih i adultnih na području zapadnog dijela Gorskog kotara (Gerovo) signifikantno viša (233 g adultni i $118 \mathrm{~g}$ juvenilni) od istovrsnika s istočnog dijela Gorskog kotara (Vrbovsko, $265 \mathrm{~g}$ adultni i $225 \mathrm{~g}$ adultni). Prijašnja istraživanja kretanja masa puhova u Gorskome kotaru (Grubešić i sur. (2004.) pokazala su da se tijekom razdoblja lova masa 
tijela ne mijenja, bez obzira radi li se o juvenilnim ili adultnim jedinkama.

Glede duljine tijela, Spangenberg (1935.) navodi kako puhovi iz Azerbajdžana imaju prosječnu duljinu tijela od 177 mm. Prema Milazzo i sur. (2003.) duljina tijela kod puhova uzorkovanih u Italiji iznosila je od $171,1 \mathrm{~mm}$ do $184 \mathrm{~mm}$, a duljina repa od 161,4 do $182 \mathrm{~mm}$. Puhovi uzorkovani u Sloveniji u istraživanju Kryštufeka i Flajšmana (2007.) u prosjeku su bili dugi $177,1 \mathrm{~mm}$, dok je prosječna duljina repa iznosila $145 \mathrm{~mm}$. Isti autori provodili su istraživanje i u drugim zemljama, tako je puhovima iz Bosne i Hercegovine prosječna duljina tijela $173,3 \mathrm{~mm}$, puhovima iz Španjolske 153,7 mm, iz Francuske 151,2 mm, a iz Gorskog kotara (Grubešić i sur. 2004.) u prosjeku od $154 \mathrm{do} 200 \mathrm{~cm}$. Popov (1960.) navodi kako su u Rusiji oko područja rijeke Volge-Kame, uzorkovani puhovi u prosjeku bili dugi 145 $\mathrm{mm}$, gdje je minimalna duljina repa iznosila $109 \mathrm{~mm}$, a maksimalna $122 \mathrm{~mm}$. Ovdje je očigledno da postoje razmjerno velike razlike u veličini puhova na pojedinim lokalitetima. Iako nam nisu u potpunosti poznati podaci o dobu godine kada su uzorci prikupljeni i o kvaliteti godine, kao niti podaci o dobi puhova, zanimljivi rezultati dobivaju se ukoliko izračunamo postotni odnos duljine repa prema ukupnoj duljini tijela. Tako ovaj podatak u ovom istraživanju iznosi 49,7 \%, što je istovjetno s podacima Milazzo i sur. (2003.). U druga dva istraživanja udio repa u duljini tijela iznosi oko 45\% (Popov 1960., Kryštufek i Flajšman 2007.), što je ponovno usporedivo s prethodno spomenutim i predmetnim istraživanjem. Iako smo utvrdili statistički značajnu razliku glede duljine i mase repa mužjaka u odnosu na iste pokazatelje kod ženki, isti nisu dostatni za primjenu u raspoznavanju spola puhova.

Životni vijek puhova je različit u pojedinim istraživanjima. Tako je prema Vekhniku (2017.) životni vijek puha znatno kraći od 4 godine, dok su pojedini autori utvrdili da je životni vijek čak od 7 do 9 godina (Morris 2004.). Iako Bieber (1998.) navodi kako je u svom istraživanju do puhova procjenjivala prema boji krzna, odnosno prema metodi Viethinghoff-Riesch i Freiherr (1960.) u našem istraživanju nismo uspjeli identificirati dob jedinke po veličini tijela i boji krzna. To je u skladu s rezultatima istraživanja pojedinih znanstvenika. Tako Pilastro i sur. (1996.) te Schlund i Scharfe (1997.) zaključuju da u populacijama srednje i zapadne Europe nije moguće identificirati dobne skupine po boji i veličini.

U ovom istraživanju ukupna masa s repom i ukupna dužina tijela ukazuje da su mužjaci u prosjeku veći. Prosječni raspon prednjih udova u korist je ženki, koji iznosi 142,90 milimetara, a kod mužjaka 139,06 milimetara. Slična situacija vidljiva je i kod raspona stražnjih udova, gdje je raspon 174,86 milimetara kod ženki, a kod mužjaka 164,01 milimetar.

\section{ZAKLJUČCI}

\section{CONCLUSIONS}

Spolni dimorfizam sivog puha nije jasno izražen. Spol jedinke je sa sigurnošću moguće utvrditi tek pregledom vanjskih spolnih organa. Statistički značajne razlike između spolova u korist mužjaka utvrđene su u slučaju mase repa i duljine tijela bez repa. Adultnu od juvenilne jednike nije moguće razlikovati na temelju veličine tijela i obojenosti krzna. Duljine tijela i ukupne mase puhova u Dalmatinskoj zagori, podudaraju se s populacijom na području Gorskog kotara. Mužjaci su u prosjeku teži i veći od ženki, dok je raspon prednjih i stražnjih udova veći u ženki. Morfološke karakteristike sivog puha dostupne iz literature, podudaraju se s vrijednostima dobivenim u našem istraživanju.

\section{LITERATURA}

\section{REFERENCES}

- Aguilar, J.P., J.Y. Crochet, K. Krivic, B. Marandat, J. Michaux, A. Mihevc, B. Sigé, S. Šebela, 1998: Pleistocene small Mammals from some karstic Fillings of Slovenia, Preliminary results, Acta Carsol, 27 (2):141-150.

- Amori, G., M. Cantini, V. Rota, 1995: Distribution and conservation of the Italian dormice. Proc. II Conference On Dormice, Hystrix It. J. Mamm., 6 (1-2):331-336.

- Anonimus 2018: Zakon o lovstvu. Narodne novine, 99.

- Anonimus 2013: Pravilnik o strogo zaštićenim vrstama. Narodne novine, 144.

- Anonimus 2008: Lovno gospodarska osnova za zajedničko otvoreno lovište, broj XVII/135 - „Vrgoračko jezero“ za razdoblje od 01. travnja 2008. do 31. ožujka 2018. godine.

- Anonimus, 2010: Pravilnik o lovostaju. Narodne novine, 67.

- Barrett-Hamilton, G.E.H., 1898: LIII. - Note on the European dormice of the genera Muscardinus and Glis, Ann. Mag. Nat. Hist., 2 (11):423-426.

- Barrett-Hamilton G.E.H., 1899: Note on the Sicilian dormice of the genera Eliomys and Glis, Ann. Mag. Nat. Hist., 3 (15):226228.

- Bieber, C., 1998: Population dynamics, sexual activity, and reproductive failure in the fat dormouse (Myoxus glis). J. Zool. Lond. 244(2): 223-229.

- Cvrtila, Ž., D. Konjević, L. Kozačinski, M. Hadziosmanović, A. Slavica, J. Margaletić, 2004: The chemical compostion of the meat of fat dormice (Glis glis L.), Eur. J. Wildlife Res., 50 (2):90-91.

- Daams, R., 1999: Family Gliridae - in: Rössner, G.E. \& Heissig, K. (eds.) - Miocene land mammals of Europe, Verlag Dr F. Pfeil, 301-318, München.

- Filippucci, M.G., T. Kotsakis, 1995: Biochemical systematics and evolution of Myoxidae, Hystrix It. J. Mamm., 6 (1-2):77-97.

- Grubešić, M., J. Margaletić, M. Glavaš, 2007: Dynamika a štruktura lovu plcha siveho (Glis glis L.) v bučinach a jedlinach Chorvatska, Folia venatoria, 36-37:173-181.

- Grubešić, M.; Krapinec, K.; Glavaš, M.; Margaletić, J., 2004: Body measurements and harvesting dynamics of the fat dor- 
mouse (Glis glis L.) in the mountainous part of Croatia. Acta Zoologica Academiae Scientiarum Hungaricae 50 (4):271-282.

- Horaček, I., 1986: Fossil records and chorological status of dormice in Czechoslovakia. Part I.: Glis glis, Eliomys quercinus, Folia Musei Rerum Naturalium Bohemiae Occidentalis, Plzeň, Zoologica, 24:49-59.

- Hürner, H., B. Kryštufek, S. Maurizio, A. Ribas, T. Ruch, R. Sommer, V. Ivashkina, J.R. Michaux, 2010: Mitochondrial phylogeography of the edible dormouse (Glis glis) in the western Palearctic region, J. Mammal., 91 (1):233-242.

- Jurczyszyn, M., 1994: Population density of Myoxus glis (L.) in some forest biotopes, Hystrix It. J. Mamm., 6 (1-2):265-271.

- Jurczyszyn, M., 2001: Reintroduction of the edible dormouse (Glis glis) in Sierakowski landscape park (Poland), Preliminary results, Trakya Univ. J. Sc. Res. Series B, 2 (2):111-114.
- Jurczyszyn, M., K. Wolk, 1998: The present status of dormice (Myoxidae) in Poland, Nat. Croat., 7 (1):11-18.

- Kryštufek, B., B. Flajšman, 2007: Polh in človek. Ekološki forum LDS, Liberalna akademija, 43-84, Ljubljana.

- Margaletić, J., M. Grubešić, K. Krapinec, K. Kauzlarić, S. Krajter, 2006: Dynamics and structure of fat dormouse (Glis glis L.) population in Croatia forests in the period from 2002 to 2004, Glas. Šum. Pokuse, posebno izdanje. 5:377-386.

- Margaletić, J., M. Moro, M. Vucelja, L. Bjedov, G. Videc, 2011: Morfološki parametri sivog puha (Glis Glis L.) uzorkovanog u šumama Gorskog kotara, CROJFE, 3(1):239-249.

- Milazzo, A., W. Faletta, M. Sara, 2003: Habitat selection of fat dormouse (Glis glis italicus) in deciduous woodlands of Sicily, Acta Zool. Acad. Sci. Hung., 49 (1):117-124.

- Morris, P. A., 2004: Dormice, Whittet Books Ltd, Suffolk, UK.

\section{Summary}

Edible dormouse (Glis glis L.) is the largest dormouse species. The edible dormouse is autochthonous game species in Croatia, and arboreal animal that is active at night. During the hunting season 2017./2018. we have collected 32 adult individuals (18 females and 14 males), on the area Dalmatian hinterland. Following sex determination, the following morphological parameters were measured: mass (total mass including tail, total mass without tail, head, tail, liver, kidney, heart, lung, digestive system and radman) and body length measurements (body length including tail, body length without tail, front and back width of the puck and tail length). Statistically significant difference between males and females was found in the length of the body without the tail $(\mathrm{p}=0.049)$ and tail mass $(\mathrm{p}=0.041)$, with males displaying greater values for both of these features. The other measured parameters did not show significant differences between sexes. Sexual dimorphism in this rodent is not pronounced, though on average males tend to be larger and heavier than females. It was not possible to differentiate adults and juveniles based on the color of the fur and the body size. Measured morphological parameters mostly coincide with results of similar research. Edible part of internal organs constitutes $5.1 \%$ of live weight (heart and lungs $1.8 \%$, livers $2.43 \%$ and kidneys $0.8 \%$ ). Non-edible part includes stomach and intestines (12.3\%), head (11.78\%), tail (4\%) and skin and metapodia (11.21\%). Sex of an individual Edible dormouse can be safely determined by looking at the external sex organs. Body length and total mass of Edible dormouse in Dalmatian hinterland is similar to the population in the Gorski Kotar region. Although we have established a statistically significant difference in the length of the body without the tail and the mass of the tail of the males compared to the same indicators in females, they are not sufficient for the use in recognizing sex of Edible dormouse.

KEY WORDS: Edible dormouse (Glis glis L.), Dalmatian hinterland, morphology, sexual dimorphism 